\title{
Carbon based DLC films: Influence of the processing parameters on the structure and properties
}

Francisco Andrés Delfín ${ }^{1}$, Sonia Patricia Brühl ${ }^{1}$ Christian Forsich ${ }^{2}$, Daniel Heim ${ }^{2}$

\author{
${ }^{1}$ Surface Engineering Group (GIS) - UTN FRCU - Ing. Pereyra 676, Concepción del Uruguay, Argentina. CP: 3260 \\ e-mail: fadelfin@gmail.com; sbruhl@frcu.utn.edu.ar \\ ${ }^{2}$ Materials Department - FH-OOE, Wels Campus - Stelzhamerstrasse 23, Wels, Austria. CP: 4600 \\ e-mail: Christian.Forsich@fh-wels.at; Daniel.Heim@fh-wels.at
}

\begin{abstract}
Hydrogenated carbon-based films, such as DLC ("Diamond Like Carbon"), have interesting properties such as excellent tribological behavior, low friction coefficient, high superficial hardness and good wear resistance; they are chemically inert and highly corrosion resistant. They are deposited by means of PACVD (plasma-assisted chemical vapor deposition) with variable film thickness. The load carrying capacity grows with the thickness, so it is possible to deposit thick films on "soft" steels (e.g. low alloyed steels). When increasing coating thickness, surface defects are generated during the deposition process compromising their excellent properties.

In this work, different metal substrates have been used to compare adhesion and quantify superficial defects: AISI 316L, DIN 42CrMo4 (AISI 4140) and Böhler K110 (AISI D2). The films were deposited at different temperatures, changing the silicon content and the coating thickness. The samples were placed in the furnace on different positions (standing, lying or up-side down).

The films were analyzed with optical and electron microscopy, 3D topography profilometer, and they were tested under sliding wear conditions. Friction coefficient and wear volume were measured, with an average friction coefficient which resulted below 0.05. A higher amount of surface defects was obtained on lying samples compared to the ones up-side down. The quantity of defects increased with the thickness of the coating and decreased with the temperature. The geometry and the growth mechanism of the defects were analyzed.
\end{abstract}

Keywords: Protective coatings, PACVD, DLC, surface defects.

\section{INTRODUCTION}

Hydrogenated amorphous carbon films (a-C:H) are a composed of carbon and hydrogen, with different $\mathrm{C}-\mathrm{C}$ and $\mathrm{C}-\mathrm{H}$ bondings, $\mathrm{sp}^{2}$ (graphite) and $\mathrm{sp}^{3}$ (diamond). The result is a hard coating, with extremely low friction coefficient and good wear resistance. Besides, these films are chemically inert in most aggressive environments and provide a good corrosion resistance making them attractive for many technological applications: mechanicals, electronical, biomed, and petrochemical and food industry [1-4].

As a drawback, these films have high internal stresses that result in low adhesion. The incorporation of silicon as coating dopant and an amorphous silicon interlayer helps to solve this problem, allowing to increase the load bearing capacity of the system; this coating is known as a-C:H:Si. Also, a higher amount of hydrogen and a drop of $\mathrm{sp} 3$ carbon bonds lead to a decrease in the film stress and helps prevent delamination [4-6].

One way of depositing these films is PACVD, using acetylene and HMDSO (hexamethyldisiloxane) as carbon and silicon precursors respectively, obtaining average deposition rates of $1 \mu \mathrm{m} / \mathrm{h}$. Some authors report that they have been able to get layers up to $58 \mu \mathrm{m}[6]$.

The advantage of the PACVD method presented here is the use of a DC plasma nitriding equipment adapted to enable a duplex process (ion nitriding and DLC deposition at once). [6-7].

However, the DLC coatings have some imperfections in the coating that negatively influence their properties, mainly in corrosion resistance and chemical inertness. These defects enable the contact between 
the film surface and the substrate, allowing corrosive substances to attack the substrate and produce crevice corrosion. Some papers related to defects in DLC films have been found, but no systematic analysis which provides an insight to characterize and eventually, determine its occurrence and growing mechanism has been made up to now [8-10].

\section{MATERIALS AND METHODS}

In this work, three different types of steels have been used as substrate: low alloy steel DIN 42CrMo4 (similar to AISI 4140), cold work steel Böhler K110 (AISI D2 like) and austenitic stainless steel AISI 316L. Samples in disk shape have been prepared (see Table 1), polished with Tegra System from Struers, using cloths with diamond solution of $3 \mu \mathrm{m}$.

Table 1: Description of the samples used in this study.

\begin{tabular}{l|c|c|c|c}
\hline \multicolumn{1}{c|}{ STEEL } & DENOMINATION & DIAMETER & THICKNESS & HARDNESS \\
\hline DIN 42CrMo4 & C & $40 \mathrm{~mm}$ & $10 \mathrm{~mm}$ & $30 \mathrm{HRc}$ \\
\hline K110 & A & $36 \mathrm{~mm}$ & $10 \mathrm{~mm}$ & $60 \mathrm{HRc}$ \\
\hline AISI 316L & SS & $25 \mathrm{~mm}$ & $5,5 \mathrm{~mm}$ & $20 \mathrm{HRc}$ \\
\hline
\end{tabular}

\subsection{PACVD deposition}

Samples were coated with a-C:H:Si using the PACVD technique (Plasma Assisted Chemical Vapor Deposition), in a commercially available ion nitriding plant, provided by the company Rübig, with a DC pulsed discharge that generates and sustains the plasma. Acetylene was used as carbon precursor and silicon was added using HMDSO. First, a silicon interlayer was deposited with a thickness of about $300 \mathrm{~nm}$ which is used as base layer for the deposition of the DLC film.

In order to control the incidence of different parameters, several processes have been carried out by changing systematically only one parameter at a time: process temperature, silicon content and deposition time. The last one is correlated to the thickness of the layer, with an average deposition rate of $1 \mu \mathrm{m} / \mathrm{h}$.

Table 2: PACVD deposition processes.

\begin{tabular}{l|c|c|c}
\hline \multicolumn{1}{c|}{ PROCESS } & TIME & TEMPERATURE & HMDSO (\%) \\
\hline DLC-Thick & $35 \mathrm{~h}$ & $450^{\circ} \mathrm{C}$ & $0.5 \%$ \\
\hline DLC-Thin & $3 \mathrm{~h}$ & $450^{\circ} \mathrm{C}$ & $0.5 \%$ \\
\hline Middle & $15 \mathrm{~h}$ & $450^{\circ} \mathrm{C}$ & $0.5 \%$ \\
\hline High Temp. & $35 \mathrm{~h}$ & $550^{\circ} \mathrm{C}$ & $0.5 \%$ \\
\hline Low Temp. & $35 \mathrm{~h}$ & $400^{\circ} \mathrm{C}$ & $0.5 \%$ \\
\hline High Silicon & $35 \mathrm{~h}$ & $450^{\circ} \mathrm{C}$ & $1 \%$ \\
\hline No Silicon & $35 \mathrm{~h}$ & $450^{\circ} \mathrm{C}$ & $0 \%$ \\
\hline
\end{tabular}

For every process, four samples of each steel grade have been placed inside the deposition chamber in different positions related to the cathode plate: lying, standing and up-side down.

\subsection{Coating thickness}

It was measured using a Calotest [11], with a $25.4 \mathrm{~mm}$ steel ball.

\subsection{Defects quantification}

Pictures of five random zones on each sample have been taken using an optical microscope, allowing defects to be observed as black dots in the picture. Defects were counted and measured using image analysis software, by which it was possible to get a classification by size and compare the amount of defects and their size in each process condition. 


\subsection{Topographical analysis}

A confocal microscope was used to measure different types of defects in the coatings, enabling to obtain topographical three dimensional images of the surface. To complete the analysis, a Tescan Vega SEM was used to get defects pictures. Also an EDX detector was used to analyze the chemical composition of the defects, helping to determine if the defect goes down to the substrate or not.

\subsection{Growing mechanism of defects}

By means of a SEM microscope equipped with FIB (Focused Ion Beam), Dual Beam Helios Nano Lab, the cross section of some defects was analyzed, in order to study their sub-superficial morphology. Also in this case the EDX was used to perform the chemical analysis in the cross section.

\subsection{Tribological behavior}

The friction coefficient and wear rate were measured using a TRIBOtechnic Tribometer, with $12 \mathrm{~N}$ load, $3000 \mathrm{~m}$ track length and a $100 \mathrm{Cr} 6$ steel ball as counterpart. Once the steady-state friction coefficient was obtained, the track was measured using confocal microscopy and wear results were analyzed using specialized software.

\subsection{Adhesion}

The adhesion strength of the deposited coatings was measured with a CSM REVETEST scratch tester. The scratch was $10 \mathrm{~mm}$ long, a Rockwell diamond indenter ( $200 \mu \mathrm{m}$ tip radius) was used, with an increasing normal load of $100 \mathrm{~N} / \mathrm{min}$. The critical load was defined as the load at which complete delamination of the coating occurred.

\section{RESULTS AND DISCUSSION}

\subsection{Coating thickness}

In Table $\mathrm{N}^{\circ} 3$ the coating thicknesses are shown, for each process group of conditions, measured by Calotest.

Table 3. Coating thickness.

\begin{tabular}{l|c|c|c|c}
\hline \multicolumn{1}{c|}{ PROCESS } & TIME & TEMPERATURE & HMDSO (\%) & THICKNESS \\
\hline DLC-Thick & $35 \mathrm{~h}$ & $450^{\circ} \mathrm{C}$ & $0.5 \%$ & $40 \mu \mathrm{m}$ \\
\hline DLC-Thin & $3 \mathrm{~h}$ & $450^{\circ} \mathrm{C}$ & $0.5 \%$ & $4 \mu \mathrm{m}$ \\
\hline Middle & $15 \mathrm{~h}$ & $450^{\circ} \mathrm{C}$ & $0.5 \%$ & $20 \mu \mathrm{m}$ \\
\hline High Temp. & $35 \mathrm{~h}$ & $550^{\circ} \mathrm{C}$ & $0.5 \%$ & $41 \mu \mathrm{m}$ \\
\hline Low Temp. & $35 \mathrm{~h}$ & $400^{\circ} \mathrm{C}$ & $0.5 \%$ & $38 \mu \mathrm{m}$ \\
\hline High Silicon & $35 \mathrm{~h}$ & $450^{\circ} \mathrm{C}$ & $1 \%$ & $38 \mu \mathrm{m}$ \\
\hline No Silicon & $35 \mathrm{~h}$ & $450^{\circ} \mathrm{C}$ & $0 \%$ & $42 \mu \mathrm{m}$ \\
\hline
\end{tabular}

The calculated mean deposition rate is slightly higher than $1 \mu \mathrm{m} / \mathrm{h}$, within the expected ranks. Coating thickness increases with temperature, whereas a rise in the silicon content in the gas mixture decreases the film thickness.

\subsection{Defects quantification}

The amount of defects has been counted in each sample through micrographs obtained with an optical microscope. In this section, the comparative data are displayed, describing the parameters that had more influence in the amount of defects.

In Figure 1, it is possible to observe the variation in density of defects for different positions of the samples inside the deposition chamber. The result of the DIN 42CrMo4 samples with thick DLC film is shown, but the same behavior was detected in all other processes. 


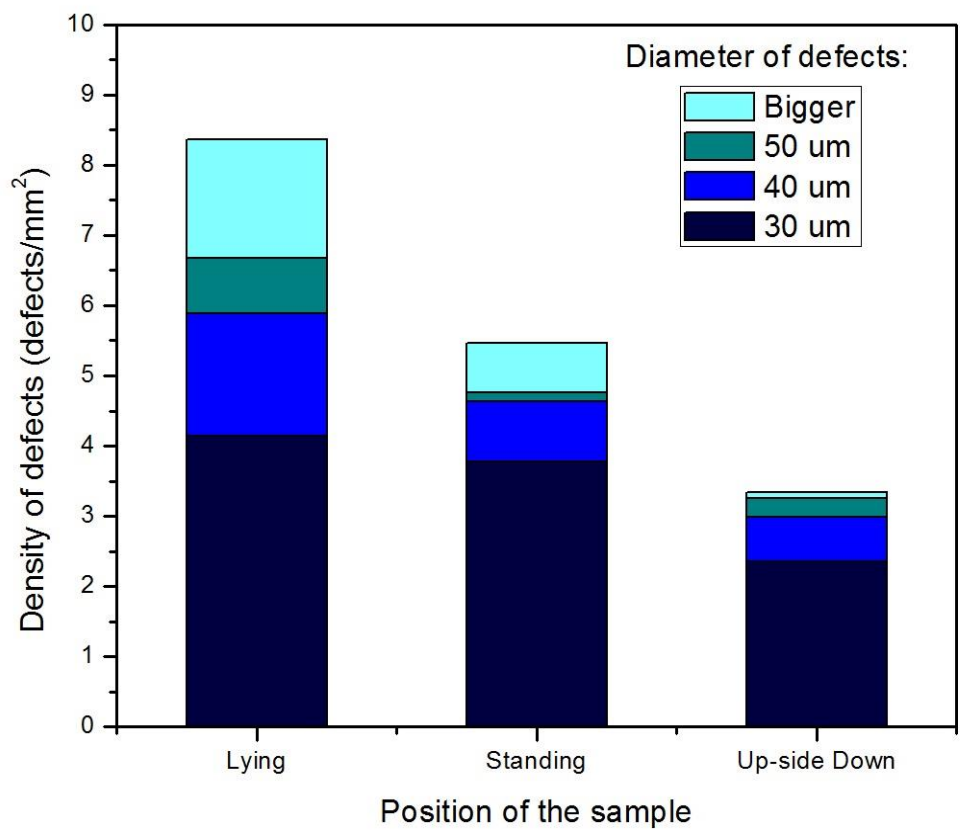

Figure 1: Density of defects in the samples coated with thick DLC over DIN 42CrMo4 on different positions inside the chamber.

In Figure 2 representative micrographs of the surface of each sample are shown according to their position inside the chamber. The most and bigger defects were produced on the lying sample (Figure 2a), less of them on the up-side down sample (Figure 2c).

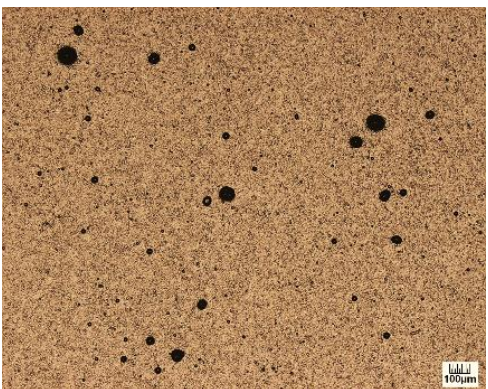

(a)

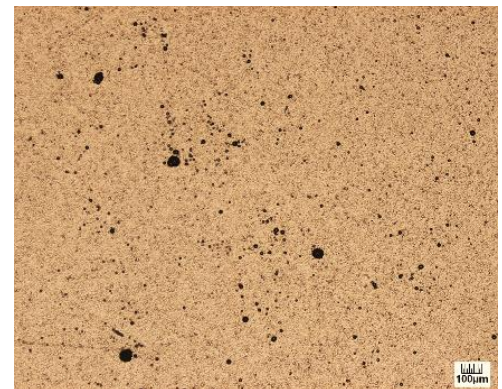

(b)

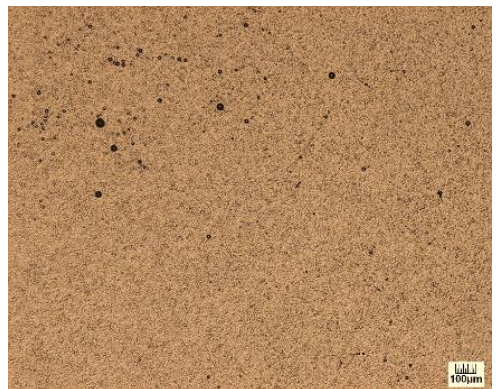

(c)

Figure 2: Optical images of different samples with thick coating over DIN 42CrMo4 in different positions inside the chamber. (a) Lying, (b) Vertical and (c) Up-side down.

Another parameter that influences defect formation is the process temperature, as shown in Figure 3 (a). When the process temperature increases, smaller and less defects are obtained on the surface. There is also a correlation between the amount and size of defects with the thickness of the coating, as shown in Figure 3 (b). More and bigger defects were observed when the coating was thicker. The same behavior was also found for the steel grades K110 and AISI 316L.

The reason for the defect formation seems to be dependent on the electrical conductivity of the coating. More defects are found when the conductivity is lower, caused by a thicker film or a lower process temperature. A DC unipolar pulsed electrical discharge was used, that requires a connection between the substrate (cathode) and the anode. As the coating has less conductivity than the substrate, the film starts to grow, creating some hot spots where the plasma concentrates and allows good conductivity, but this causes a defect in each spot. 


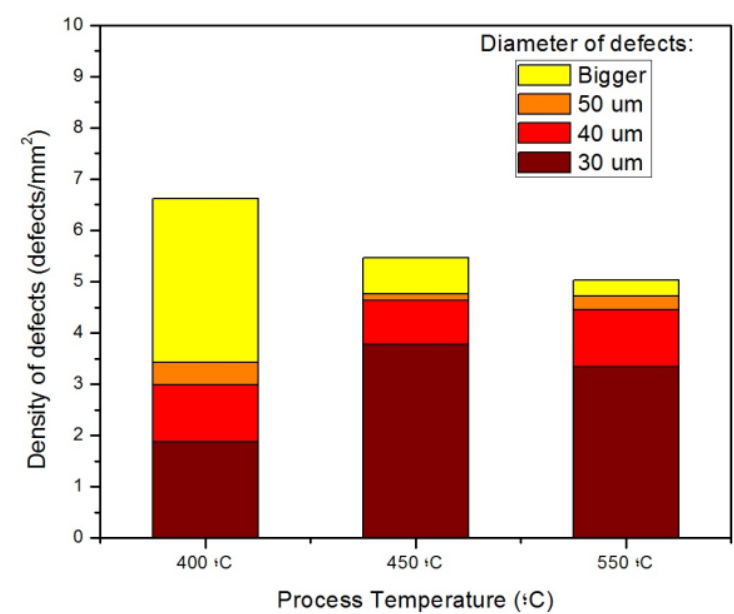

(a)

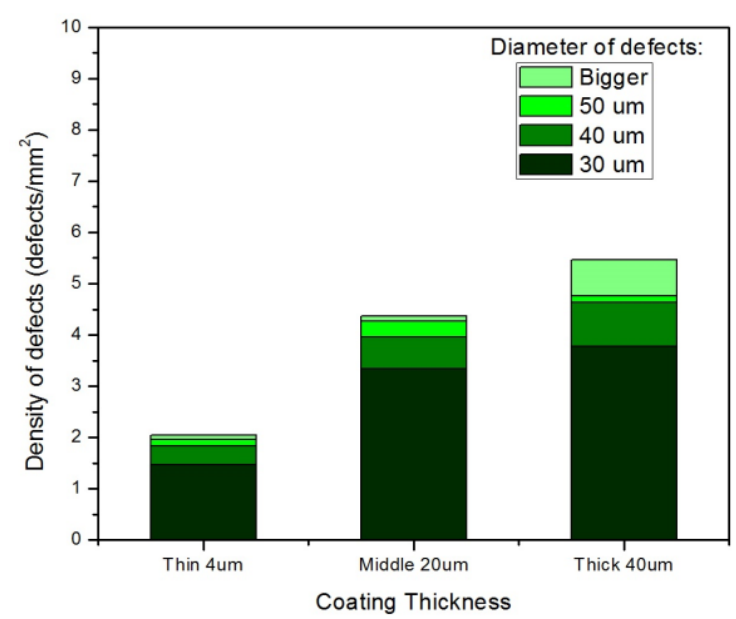

(b)

Figure 3: (a) Density of defects for coatings with different process temperature over DIN 42CrMo4. (b) Density of defects for different coating thickness over DIN 42CrMo4.

\subsection{Morphological analysis of defects}

A SEM analysis revealed the presence of different types of defects on the coating surface. The most common defect by far is the protuberance, as it can be seen in Figure 4 (a), they even got stuck together to perform much bigger defects or clusters as shown in Figure 4 (b). An EDX analysis of these defects revealed that their chemical composition is the same as the coating. Holes were also found on the surface, as it can be seen in Figure 4 (c), and it was determined that some of them could even reach the substrate. Inside these defects, some impurities have been found using EDX.

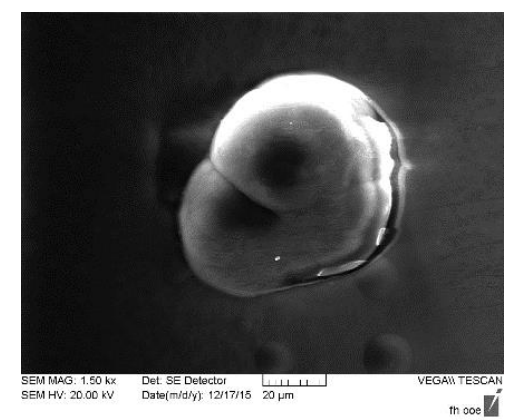

(a)

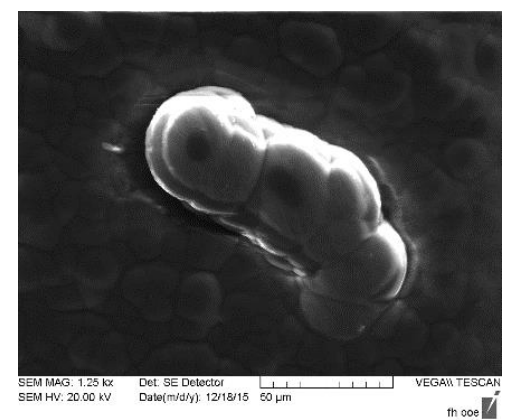

(b)

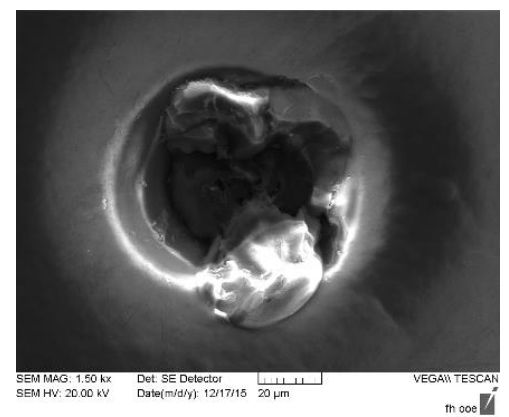

(c)

Figure 4: Different defect morphologies for thick DLC coatings on DIN 42CrMo4.

\subsection{Defect growing mechanism}

By means of FIB, it was possible to analyze the cross section of the thin coatings $(4 \mu \mathrm{m})$, where three kinds of defect growing mechanisms were found. In the first case, shown in Figure 5 (a), the coating follows the surface imperfections, such as porosity, grinding, sandblasting, etc.

In Figure 5 (b) a second case is shown, where tiny dust particles are deposited on the substrate and act further as nucleation points for the film growing. Finally a third type of defect was detected, shown in Figure 5 (c), where pores have been formed near some impurities whereas the silicon interlayer seems to be unaffected. 


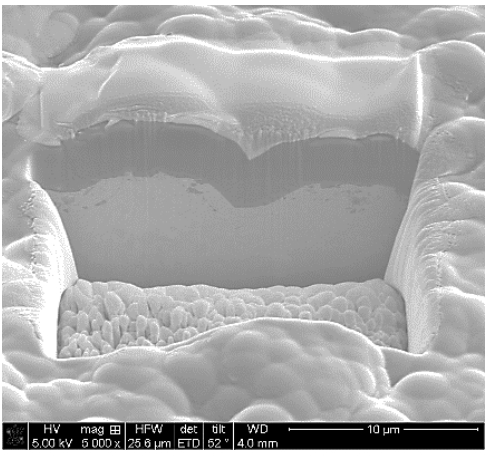

(a)

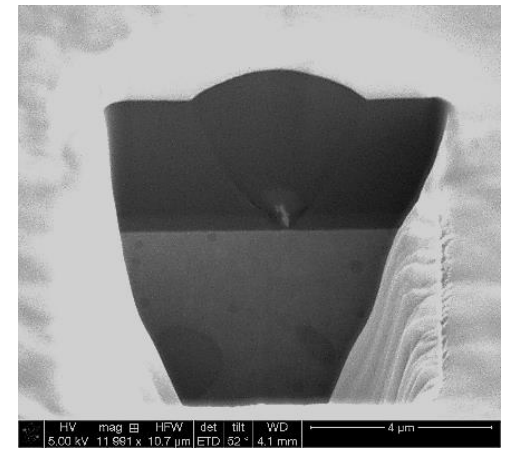

(b)

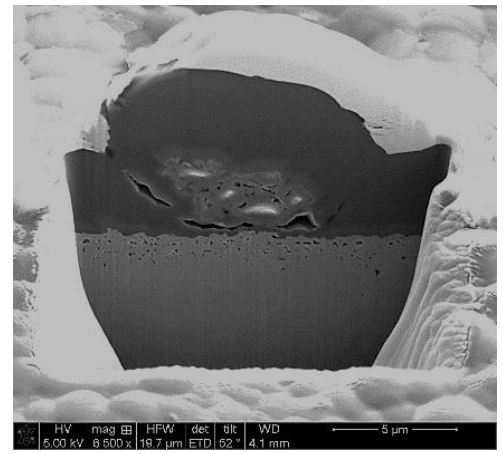

(c)

Figure 5: Sub-superficial morphology of different types of defects. (a) Thin coating on DIN 42CrMo4. (b) Thin coating on Böhler K110 and (c) Thin coating on nitrided DIN 42CrMo4.

An EDX analysis was performed in the FIB cross section, revealing that the chemical composition of the coating does not seem to be affected in the first two cases (Figure 5 a and b), while in the third case (Figure $5 \mathrm{c}$ ) some impurities such as calcium and aluminum have been found. The sub-superficial morphology of these kinds of defects and the impurities found inside them lead to the hypothesis, that these defects become deep holes after an external force which cuts them off, looking like the holes found in the SEM analysis of the surface (Figure $4 \mathrm{c}$ ). It can also be considered that something similar happened to the protuberances in Figure 5 (b), due to the weakness in grip between the coating and the nucleated part that become the protuberance.

\subsection{Tribology}

Pin-on-Disk test were carried out on all samples covered with the different coatings. No difference was observed in the tribological behavior when the substrate and the coating process parameters were changed, except for the silicon content variation that produced a change in the friction coefficient and the wear rate, as it is shown in Figure 6.

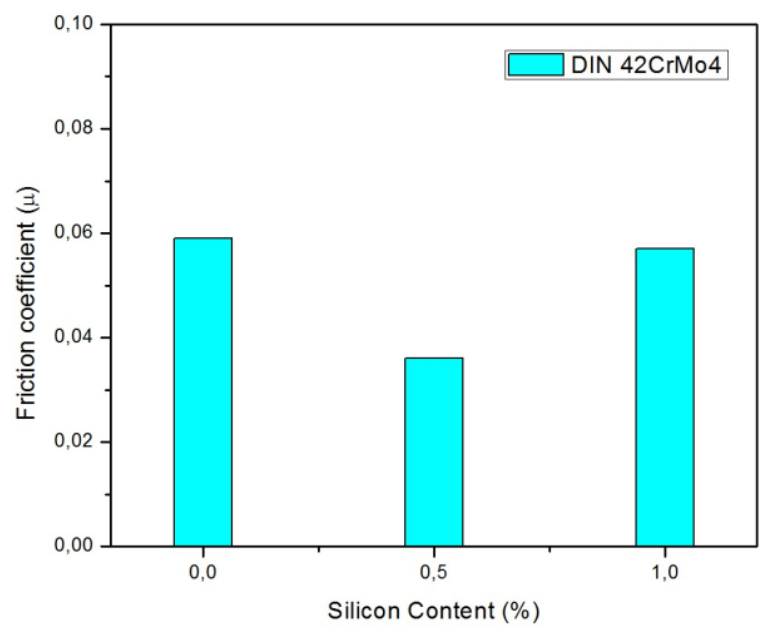

(a)

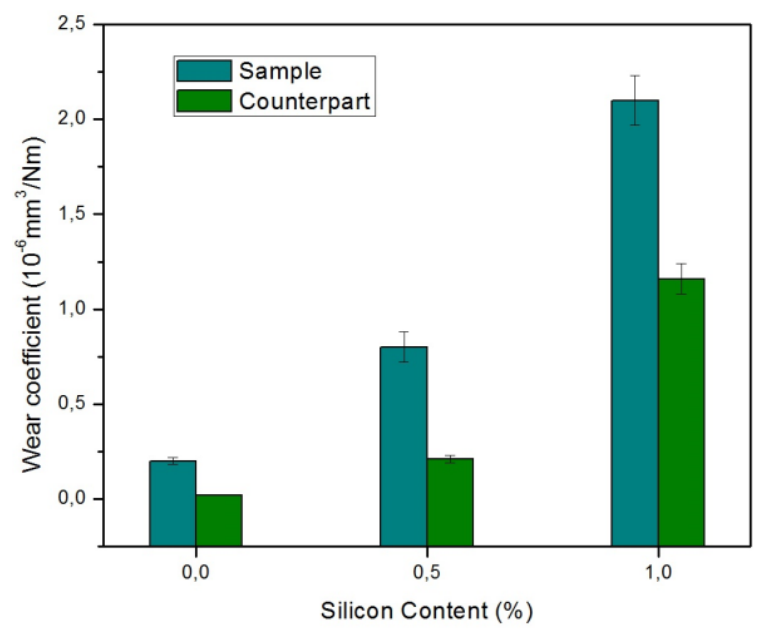

(b)

Figure 6: Tribological results for the DIN 42CrMo4 samples. (a) Friction coefficient. (b) Wear rate.

The average friction coefficient was 0.035 regardless the steel grade or the pre-treatment of the substrate. The average wear rate on the sample was $0.75 \times 10^{-6} \mathrm{~mm}^{3} / \mathrm{Nm}$. 


\subsection{Adhesion}

Scratch tests were performed on samples with different thickness. As expected, the load carrying capacity increases with the film thickness. The critical load of the coating linearly rises with increasing film thickness. In Figure 7, the experimental points together with the fitting curves are shown.

It is possible to enhance the load carrying capacity by performing a hardening pre-treatment such as ion nitriding before the coating deposition, a process better known as duplex treatment. The nitriding pretreatment provides a hardness gradient in the substrate that improves the interface substrate-interlayercoating. As it is also shown in Figure 7, for all film thicknesses, the critical load was higher.

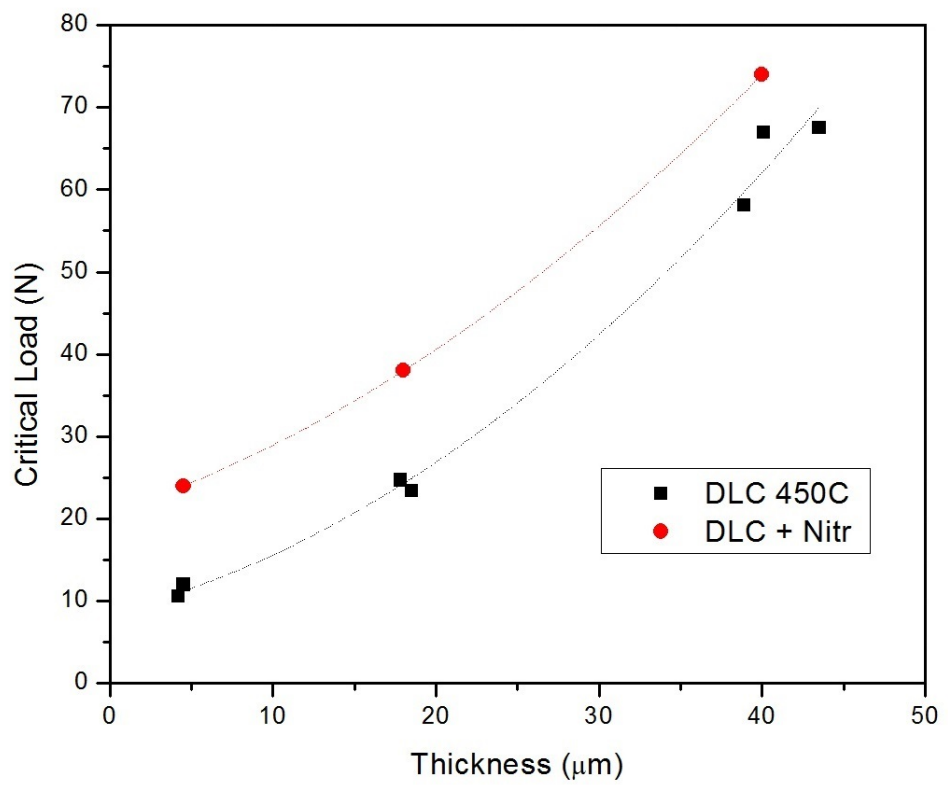

Figure 7: Critical load vs. coating thickness. Substrate: DIN 42CrMo4.

\section{CONCLUSIONS}

There is a clear correlation between the position of the sample inside the process chamber and the amount of defects that appear on the sample surface, being the best option the up-side down position, which yielded the smaller density of defects. A process at the lowest temperature generated more and bigger defects, which diminish when temperature grows up. Finally, the thin coatings turned out to have less quantity of defects than the thick coatings.

A hypothesis that can be proposed is about the relation between the growth of defects and the conductivity of the coating, which increases with the thickness (when the film grows) and diminishes with temperature, i.e. the higher the temperature, the higher the conductivity.

The most common morphology of the defects found on the DLC surface is the protuberance, which can also form groups like protuberance islands or clusters. Some holes going down to the substrate have also been found and they can be caused by the removal of these protuberances.

Deposition parameters, presence of defects and film thickness do not affect the coefficient of friction nor was the wear rate, except for the case of the silicon content, which can reduce the coefficient of friction adding $0.5 \%$, but at the same time, wear rate slightly increased. Adhesion resulted better with the increase of thickness and the use of nitriding as pre-treatment.

\section{ACKNOWLEDGMENTS}

To the Surface Engineering Group, teachers and students.

To the Upper Austria University of Applied Sciences, Wels Campus, and the Materials Department.

To the Functional Materials Department of Saarland University, Germany.

To the OeAD, Austrian Agency for International Cooperation in Education and Research, for the scholarship of F. Delfin that made this research possible. 


\section{BIBLIOGRAPHY}

[1] DONNET, C., ERDEMIR, A., Tribology of Diamond-Like Carbon Films: Fundamentals and Applications, 1 ed., New York, Springer, 2008.

[2] ROBERTSON, J., "Diamond-like amorphous carbon", Material Science and Engineering, v. 37, n. 2-4, pp. 129-281, May 2002.

[3] DALIBON, E.L., HEIM, D., et al., "Characterization of thick and soft DLC coatings deposited on plasma nitrided austenitic stainless steel”, Diamond \& Related Materials, v. 59, pp. 73-79, Oct. 2015.

[4] GASCO OWENS, A., BRÜHL, S.P., et al., "Comparison of Tribological Properties of Stainless Steel with Hard and Soft DLC Coatings", Procedia Materials Science, v. 9, pp. 246-253, Apr. 2015.

[5] CEMIN, F., BOEIRA, C.D., FIGUEROA, C.A., "On the understanding of the silicon-containing adhesion interlayer in DLC deposited on steel", Tribology International, v. 94, pp. 464-469, Feb. 2016.

[6] FORSICH, C., DIPOLT, C., et al., "Potential of thick a-C:H:Si films as substitute for chromium plating", Surface \& Coatings Technology, v. 241, pp. 86-9, Feb. 2014.

[7] FORSICH, C., HEIM, D., MUELLER, T., "Influence of the deposition temperature on mechanical and tribological properties of a-C:H:Si coatings on nitrided and postoxidized steel deposited by DC-PACVD", Surface \& Coatings Technology, v. 203, n. 5-7, pp. 521-525, Dec. 2008.

[8] BERNLAND, K., KÖHLER, B., et al., "Combined FIB technique with acoustic microscopy to detect steel-DLC interface defects", Diamond \& Related Materials, v. 15, n. 9, pp. 1405-1411, Sep. 2006.

[9] HADINATA, S.S., LEE, M.T, et al., "Electrochemical performances of diamond-like carbon coatings on carbon steel, stainless steel, and brass", Thin Solid Films, v. 529, pp. 412-416, Feb. 2013.

[10] YATSUZUKA, M., TATEIWA, J., UCHIDA, H., "Evaluation of pinhole defect in DLC film prepared by hybrid process of plasma-based ion implantation and deposition", Vacuum, v. 80, n. 11-12, pp. 13511355, Sep. 2006.

[11] HERNANDEZ, L.C., PONCE, L., et al., "Nanohardness and Residual Stress in TiN Coatings", Materials, v. 4, n. 12, pp. 929 - 940, May 2011. 